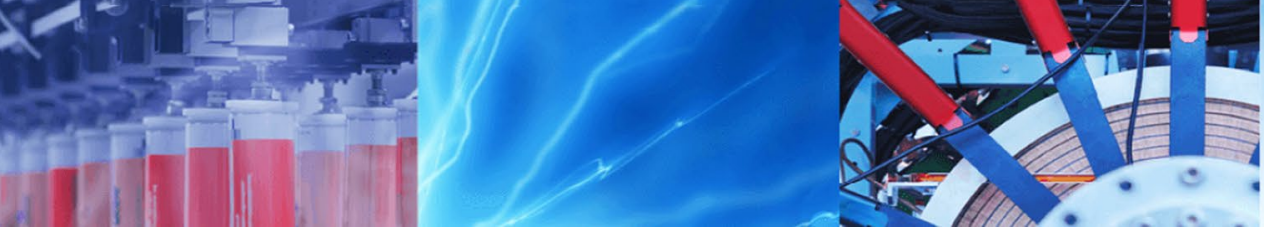

Research Article

\title{
Ozone production and chemical kinetic corona discharge of pure gas $\mathrm{O}_{2}$ species
}

\author{
Djaoued Mekkioui $^{1}$ (D) Ines Sarah Medjahdi ${ }^{1}$
}

Received: 12 November 2019 / Accepted: 5 March 2020 / Published online: 18 March 2020

(c) Springer Nature Switzerland AG 2020

\begin{abstract}
The work presented in this paper aims to study the chemical kinetics of some species previously chosen by corona discharge at atmospheric pressure $P=1 \mathrm{~atm}$ and at room temperature $T=300^{\circ} \mathrm{K}$, carried out in wire-cylinder geometry in a pure gas $\mathrm{O}_{2}$. In this perspective, a computer program is designed, efficient in time and space, is used to solve the system of fluid dynamic classical equations based on the resolution of the Boltzmann equation. It participates also, in the chemical kinetics of the gas including the equations of continuity, momentum and energy. For numerical resolution, the flux-corrected transport method is applied successfully to electric discharge, and the generated species of pure gas $\mathrm{O}_{2}$ kinetics are obtained. The reactivity of the gas takes into account nine species that interact according to 23 reactions selected in a way calculated to favor the most dominant. The chosen reduced field values are 100,120,140,160, 180 and $200 \mathrm{Td}$. The results obtained show an evolution closely related to the reduced electric field, and the production of ozone is accompanied by the appearance and disappearance of other species.
\end{abstract}

Keywords Corona discharge $\cdot$ Reduced field $\cdot$ Chemical kinetic · Ozone

\section{Introduction}

Plasma is a partially or totally ionized gas composed of charged particles (electrons and ions) and neutrals. This gas is recognized as the fourth state of matter. Laboratory plasma or plasma discharge can be generated by several energy sources ranging from cosmic rays to microwave sources. They can be classified according to the temperature, as they can be classified according to the pressure. Plasma applications are now used in high-technology sectors and scientific research where industrial issues and socioeconomic benefits are important. Their scope is very broad. Examples include the microelectronics industry, agronomy, metallurgy [1-4], etc. The discovery of new applications in biomedical, gas processing and space propulsion has guided advent of miniaturization of plasma sources [5-7]. Plasma techniques are generated most of the time by the electrical rupture of neutral gas in the presence of an external electric field. In addition, the fundamental problems of gas discharges concern the interaction between the carrier gas (neutral particles) and the ionized gas (electrons and ions). Indeed, the transfer of energy from the charged particles to the neutral particles plays a decisive role in the evolution of the discharge. The corona discharge is developed between two asymmetrical electrodes in a gaseous medium with a non-uniform field $[8,9]$. Through its propagation, the electric field discharge leaves behind a plasma trail (ionized channel), consisting of neutral and charged species. Several studies have been conducted in order to explain the different mechanisms involved in the formation, development of these species. The corona discharge is used for several interesting purposes such as electrostatic painting [10], commercial ozone generation [11] and depollution [12]. Ozone has

Djaoued Mekkioui, mekkioui_2018@yahoo.com | 'Department of Physics, Faculty of Sciences, University of Tlemcen, P.B. 119, 13000 Tlemcen, Algeria. 
been studied and applied in a remarkable way for the treatment of water because of its high oxidation power and the ability to participate in many chemical reactions with organic or inorganic substances $[13,14]$. Small concentrations of ozone can be produced by radiation (UV), or by the chemical method, etc. However, large amounts of ozone can be produced by high-voltage electrical discharges. Moreover, the generation of ozone $\mathrm{O}_{3}$ by electric discharge, in particular the corona type in industrial quantities in a dry gas containing oxygen, constitutes a very interesting nonthermal plasma process and most used compared with other processes $[15,16]$. The complexity of the phenomena and their coupling induce the high difficulty describing completely the behavior of the electric discharge. Many experimental methods may give the essential elements to the comprehension of physical phenomena due to the electric discharge confined in a plasma reactor, respectively, to different neutral and charged chemical species in the case of partial ionization. These experimental observations induce two theories where mathematic equations are formulated. Otherwise, this approach is limited where one principal parameter may not be analyzed directly and may be agreed by an additional simple hypothesis. Globally, the electric discharge dynamic study is complex and its numerical simulation in gases is a difficult task, since many equations must be simultaneously solved. Therefore, different simplifications are usually introduced in order to reduce the complexity of the problem. For example, wire-cylinder streamer corona discharge has been simulated in [17-19] assuming that electronic injections, with azimuthal symmetry, occurred at certain sites along the corona wire. The injected electron density was given as an empirical law, and the dependence of reaction rate constants with the electric field was not taken into account. In [20,21], the authors have used a corona plasma model to determine the electron and ion densities. A similar approach has recently been used in [22] to investigate ozone generation in air using wire-cylinder corona discharge. Otherwise, the authors in [23-25] have investigated the generation of ozone in wire-cylinder geometry using negative and positive corona. The electrical discharge was modeled as stationary and symmetrical around the corona wire, as done by other investigators [20-22]. Then, in this paper appropriate codes were developed and many numerical simulations are given in order to complete the analytic and experimental research of the particles. The analysis method developed here in order to describe qualitatively and quantitatively the chemical kinetic of species generated in a corona discharge is based on the resolution of the Boltzmann equation. The hydrodynamics-related macroscopic equations are expanded and implemented numerically (density, energy, quantity of movement, etc.). Since the flux-corrected transport (FCT) method is applied successfully to electric discharge, the generated species of pure gas $\mathrm{O}_{2}$ kinetics are obtained.

\section{Background and mathematical equations}

\subsection{Boltzmann equation}

The analysis method developed here to describe qualitatively and quantitatively the chemical kinetic of species generated in a corona discharge is based on the resolution of the Boltzmann equation. The hydrodynamics-related macroscopic equations are expanded and implemented numerically (density, energy, quantity of movement, etc.). In order to follow the kinetic evolution of the plasma particles (electrons, ions and neutrals), a local function $\overrightarrow{\boldsymbol{f}}(\overrightarrow{\boldsymbol{r}}, \overrightarrow{\boldsymbol{w}}, t)$ represents the velocity distribution function of a collection of $n$ particles of mass $m$. The evolution of such function in space is given by the Boltzmann equation (1) [26]:

$\frac{\partial}{\partial t} \overrightarrow{\boldsymbol{f}}(\overrightarrow{\boldsymbol{r}}, \overrightarrow{\boldsymbol{w}}, t)+\overrightarrow{\boldsymbol{w}} \vec{\nabla}_{\mathbf{r}} \overrightarrow{\boldsymbol{f}}(\overrightarrow{\boldsymbol{r}}, \overrightarrow{\boldsymbol{w}}, t)+\frac{F}{m} \vec{\nabla}_{\mathbf{w}} \overrightarrow{\boldsymbol{f}}(\overrightarrow{\boldsymbol{r}}, \overrightarrow{\mathbf{w}}, t)=\left\{\frac{\partial}{\partial t} \overrightarrow{\boldsymbol{f}}(\overrightarrow{\boldsymbol{r}}, \overrightarrow{\boldsymbol{w}}, t)\right\}_{\text {Coll' }}$

where $\vec{f}(\overrightarrow{\boldsymbol{r}}, \overrightarrow{\boldsymbol{w}}, t)$ is the distribution function of velocities of a collection of $n$ particles of mass $m$; $\overrightarrow{\boldsymbol{w}}$, the particle velocity; $\frac{\vec{F}}{\boldsymbol{m}^{\prime}}$, the external force acceleration to particles of mass $m ; \vec{\nabla}_{\mathbf{r}}$, the position gradient in space; $\vec{\nabla}_{\mathbf{w}}$, the velocity gradient; and $\frac{\partial}{\partial t} \overrightarrow{\boldsymbol{f}}(\overrightarrow{\boldsymbol{r}}, \overrightarrow{\boldsymbol{w}}, t)$, the collision distribution function variation ratio.

\subsection{Conservation equation of the density $n(\vec{r}, t)$}

In this equation, $\boldsymbol{V}(\overrightarrow{\boldsymbol{r}}, \boldsymbol{t})$ represents the macroscopic average velocity. The conservation equation is given by

$\frac{\partial}{\partial t} \boldsymbol{n}(\overrightarrow{\boldsymbol{r}, t})+\vec{\nabla}_{\mathbf{r}}\{\boldsymbol{n}(\overrightarrow{\boldsymbol{r}}, t) \cdot \boldsymbol{V}(\overrightarrow{\boldsymbol{r}}, t)\}=\boldsymbol{S}$,

where

$S=\iiint\left\{\frac{\partial}{\partial t} \overrightarrow{\boldsymbol{f}}(\overrightarrow{\boldsymbol{r}}, \overrightarrow{\boldsymbol{w}}, t)\right\}_{\text {coll }} \boldsymbol{d}^{3} w$. 
If the number of interactions between particles is constant, then $S=0$. In the other case, which is the discharge in the gas, $S$ is the number of creation and disappearance of particles by ionization, attachment and charge exchanges.

\subsection{Conservation equation of each species density}

The evolution equation of the jth species density is given by

$\frac{\partial n_{j}}{\partial t}+\operatorname{div}\left\{n_{j} V_{j}(T)\right\}=S_{j}(T)$

with $n_{j}$ being the $j$ th species density; $\frac{\partial n_{j}}{\partial t}$, the time rate variation of the $j$ th species density in gas mixture; $T$, the gas temperature; $\operatorname{div}\left\{n_{j} V_{j}(T)\right\}$, the transport at diffusion velocity $V_{j}(T)$ of the jth species in gas mixture; $S_{j}(T)$, the variation rate of $n_{j}$ due to chemical kinetics.

\subsection{Chemical kinetics equations}

The reactivity of the gas (i.e., chemical kinetics) is taken into account in the source term $S_{j}(T)$ of each density conservation equation. In the case where the chemical reactions are reactions with two bodies, $S_{j}(T)$ is given at time $t$ by the relation:

$S_{j}(T)=\sum_{\mathrm{a}} \pm k_{\mathrm{a}}(T)\left(n_{\mathrm{q}} n_{\mathrm{l}}\right)_{\mathrm{a}^{\prime}}$

where $k_{\mathrm{a}}(T)$ is the reaction coefficient for chemical reaction number $a$ and $\left(n_{\mathrm{q}} n_{1}\right)$ is the product of the densities of the species $q$ and $/$ which interact in the reaction.

The relation (4) shows that certain reaction coefficients can depend exponentially on the temperature of the gas. Under these conditions, the source term is very sensitive to any change in temperature and can therefore lead to large variations in the production and disappearance rates of the species $j$ concerned. This has direct repercussions on the whole dynamics of the gas because of the very strong interconnection between the equations of conservation. The complexity of the chemical kinetics model also comes from the very different characteristic timescales of each chemical reaction. Therefore, the coherent evolution of the whole system of equations must be based on the lowest timescales to integrate the rapid variations of certain species.

\section{Numerical method for transport equation resolution}

For each particle, a transport equation is given by Eq. (5):

$\frac{\partial \emptyset}{\partial t}+\nabla \cdot(\emptyset w)=S_{\emptyset}$

where $\emptyset(r, z, t)$ is the transported value (density, movement quantity or energy) and $S_{\varnothing}(r, z, t)$ is the transport equation corresponding source term.

The transport equations are closely coupled and are discretized by finite volume method [27] and corrected by the method developed in [28-30]. The numerical treatment of Eq. (5) needs the discretization of the continued space which leads to defining the size of control volume or cell. Otherwise, the cell's dimensions vary according to the whole of the fluid ( microns for micro-systems to kilometers for atmospheric phenomena) and upon precision required. Therefore, the exact density computation in control volume assumes that there is no significant particle at any point in this volume. The time discretization is to move from time $t$ to time $(t+\Delta t)$ assuming a linear evolution of transport phenomena between these two times. The spatial discretization is given by spatial finite volume elements and integrating Eq. (5) in such elements [27]. The equations of discretization ensure much lossless in information, which are responsible for numerical fluctuations (dissipation, oscillation and numerical diffusion). Hence, there are many numerical methods which limit these fluctuations. For more precision in computation, the FCT method [28-30] is applied for flux correction. Thus, the FCT tehnique is efficient in order to counter the numerical diffusion, higher gradients and higher amplification. Actually, this method is very efficient for the numerical treatment of macroscopic equations.

\subsection{FCT technique principle}

The main idea of the method (FCT) is to apply corrective scattering to a dispersive transport scheme, locating scattering only in regions where meaningless oscillations tend 
to form as a result of scattering. This corrective diffusion is nonlinear because its value depends on the values of the charge or mass density $\rho$. Diffusion is applied conservatively, so that when an amount of fluid is subtracted from a point, it is offset by an equal amount added elsewhere. Thus, small quantities of densities are extracted locally from one point to another without, however, altering the overall system by gains or losses. In summary, the correction technique (FCT) comprises two main stages: a transport stage (Step I) followed by the anti-diffusion or correction stage (Step II). The two stages are conservative (i.e., no creation or disappearance of particles in a nonphysical way) and strictly positive. Their interaction allows the treatment of strong gradients without generating the usual dispersive oscillations [28-30].

\section{Numerical results and discussion}

A corona discharge traversing a pure $\mathrm{O}_{2}$ gas is applied which depends on electrode geometries (anode = wire, cathode $=$ cylinder), magnitude and frequency of the voltage, electrical space charges, materials and gas parameters. The initial pressure is $10^{5} \mathrm{~Pa}$ and the temperature is $300^{\circ} \mathrm{K}$. The reactivity of the gas takes into account nine species, namely the electrons, the $\mathrm{O}_{2}, \mathrm{O}_{3}$ molecules, the $\mathrm{O}$ atom, the $\mathrm{O}_{2}$ excited states, $\mathrm{O}(1 \mathrm{D}), \mathrm{O}_{2}$ $\left(\mathrm{A}_{1}\right)$, and the $\mathrm{O}^{-}$negative ions, $\mathrm{O}_{2}{ }^{-}$and $\mathrm{O}_{3}{ }^{-}$reacting with each other following 23 previously selected chemical reactions. The reduced electric field $\left(\frac{E}{N}\right)$ varies between 100 and $200 \mathrm{Td}\left(1 \mathrm{Td}=10^{-21} \mathrm{~V} \mathrm{~m}^{2}\right)$.

\subsection{Time Evolution of pure gas $\mathrm{O}_{2}$ species}

In this section, numerical resolution of the Boltzmann equation, space and time evolution along discharge axis of species densities versus the reduced field $\left(\frac{E}{N}\right)$ values are performed. The obtained results for $\mathrm{O}, \mathrm{O}_{3}, \mathrm{O}_{2}\left(\mathrm{~A}_{1}\right)$, $\mathrm{O}_{2}^{-}, \mathrm{O}^{-}$and $\mathrm{O}_{3}^{-}$species are illustrated, respectively, in Fig. 1. Otherwise, Fig. $1 \mathrm{a}$, b shows the density evolution of primary radicals $\left(\mathrm{O}, \mathrm{O}_{3}\right)$ and their chemical reactivity evolution. The radical $O$ is created abundantly by electronic impact with $\mathrm{O}_{2}$ molecules by the dominant reaction after discharge crossing in the pure gas: $\mathrm{e}+\mathrm{O}_{2} \rightarrow \mathrm{e}+\mathrm{O}+\mathrm{O}[31]$. The species is generated quickly but is consumed rapidly too in gain of ozone $\mathrm{O}_{3}$. This is quite possible only to a limit voltage and a reduced field $\left(\frac{E}{N}\right)=120 \mathrm{Td}$ (Fig. 1a). For ozone molecule $\mathrm{O}_{3}$, we notice an intensive creation followed by its quiet concentration stability. This is favorable by the reduced field high intensity according to $\mathrm{O}+\mathrm{O}_{2}+\mathrm{O}_{2} \rightarrow \mathrm{O}_{3}+\mathrm{O}_{2}$ [19] and $\mathrm{O}+\mathrm{O}_{3} \rightarrow \mathrm{O}_{2}+\mathrm{O}_{2}$ [31]. This phenomenon is inversed in the case of less reduced field intensity because there is $\mathrm{O}$ less ratio creation. And, it is favorable to $\mathrm{O}_{3}$ apparition until the reverse equation takes place (Fig. 1b). For the excited state $\mathrm{O}_{2}\left(A_{1}\right)$, we notice that it is created with a stable manner at $100 \mathrm{Td}$. Otherwise, upon this field intensity, the generation is followed by a direct consummation. This excited state contributes to the regeneration of $\mathrm{O}_{2}$ and $\mathrm{O}$ when applying high voltage with the reactions: $\quad \mathrm{O}_{2}\left(\mathrm{~A}_{1}\right) \rightarrow \mathrm{O}_{2}+2 \mathrm{O}_{2} \quad$ and $\mathrm{O}_{2}\left(\mathrm{~A}_{1}\right) \rightarrow \mathrm{O}_{2}+2 \mathrm{O}_{2}+\mathrm{O}$. The negative ions have an important interest in the gas comportment because the particle is dedicated to the generation or degradation of each other directly or indirectly (Fig. 1C). The $\mathrm{O}_{3}^{-}$species, which are created by electronic impact, are closely attached to $\mathrm{O}$ species. Then, the $\mathrm{O}_{3}^{-}$species are produced abundantly since the reduced electric field is increased in order to create $\mathrm{O}_{2}^{-}$particles according to the reaction: $\mathrm{O}_{3}^{-}+\mathrm{O} \rightarrow \mathrm{O}_{2}^{-}+\mathrm{O}_{2}$. The increase in $\left(\frac{E}{N}\right)$ is closely related since these species appear at $120 \mathrm{Td}$ (Fig. 1d). The $\mathrm{O}^{-}$species are recombined to gas $\mathrm{O}_{2}$ molecules or to ozone in order to produce $\mathrm{O}_{2}^{-}$species according to

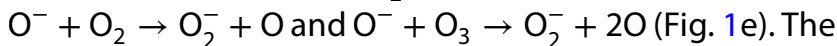
$\mathrm{O}_{2}^{-}$species are responsible for $\mathrm{O}^{-}$or $\mathrm{O}_{2}$ creation according to $\mathrm{O}_{2}^{-}+\mathrm{O} \rightarrow \mathrm{O}^{-}+\mathrm{O}_{2}$. This case appears at $100 \mathrm{Td}$, begins at $120 \mathrm{Td}$ and increases for higher reduced field. The density of this particle is important compared to that of the other ions (Fig. 1f).

\subsection{Time evolution of each species versus the reduced electric field $\left(\frac{E}{N}\right)$}

In this section, the time evolution of each species versus the reduced electric field $\left(\frac{E}{N}\right)$ in the range [100 Td, $200 \mathrm{Td}$ ] is illustrated in Fig. 2. The density conservation histograms of each species upon the reduced electric field are shown in Fig. 3. At $100 \mathrm{Td}$, the production and consummation processes are inexistent for $\mathrm{O}^{-}, \mathrm{O}_{2}\left(\mathrm{~A}_{1}\right), \mathrm{O}, \mathrm{O}_{3}{ }^{-}$species and quite sensible for $\mathrm{O}_{3}$ and $\mathrm{O}_{3}{ }^{-}$components (Fig. 2a). At $120 \mathrm{Td}$, it is followed by the stability of ozone $\mathrm{O}_{3}$ reaction and the excited state $\mathrm{O}_{2}\left(A_{1}\right)$, but it is favorable for the creation O (Fig. 2b). At $140 \mathrm{Td}$, the behavior is inversed and it 


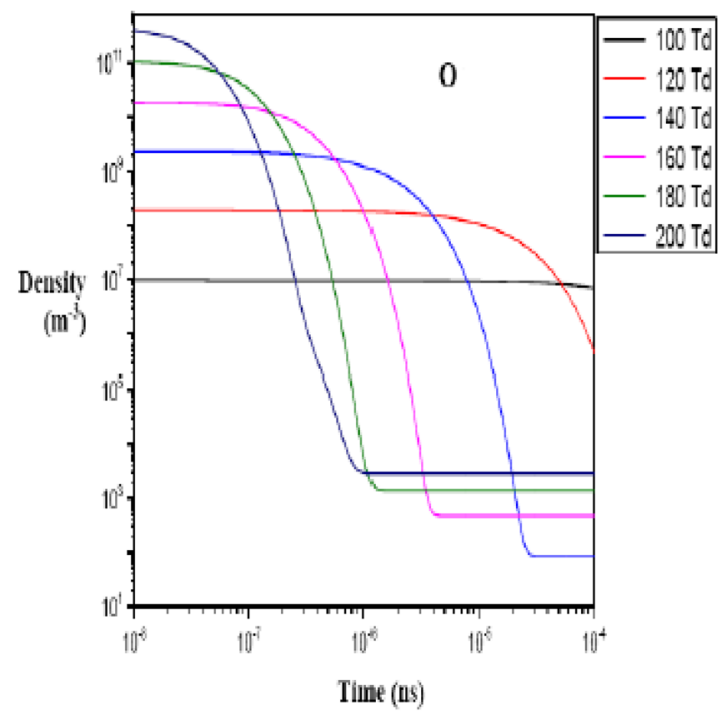

(a)

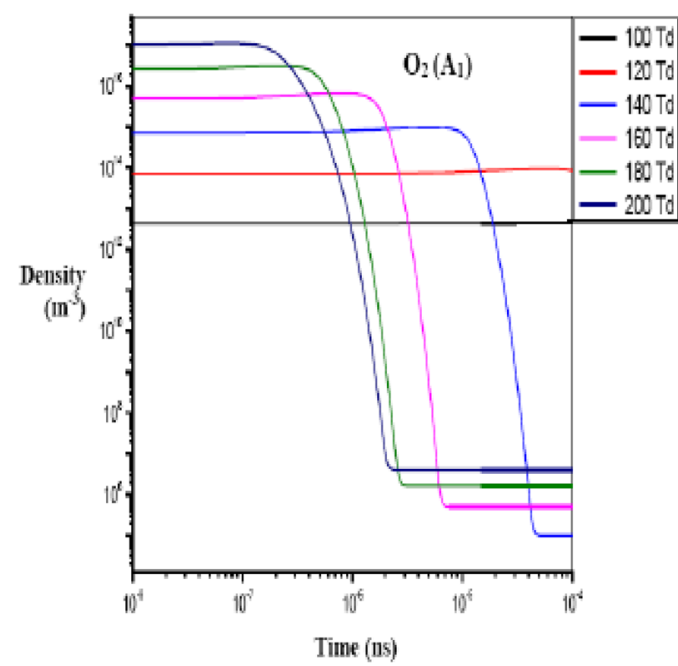

(c)

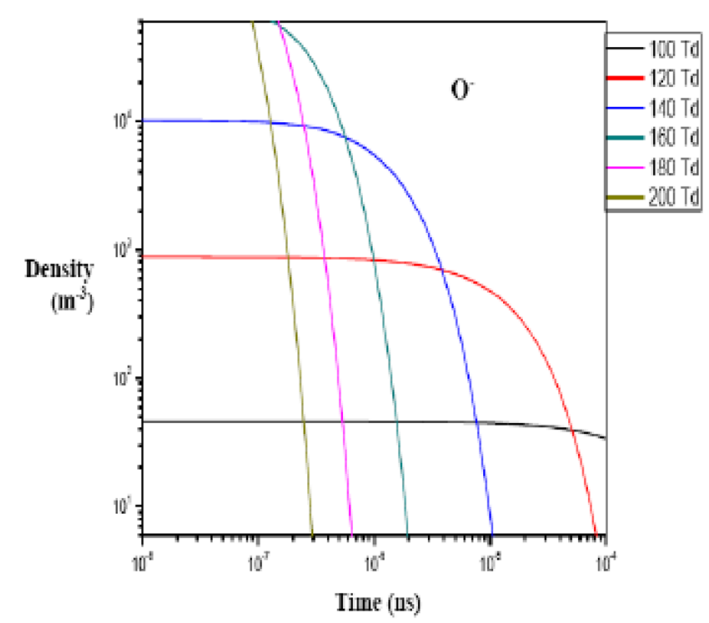

(e)

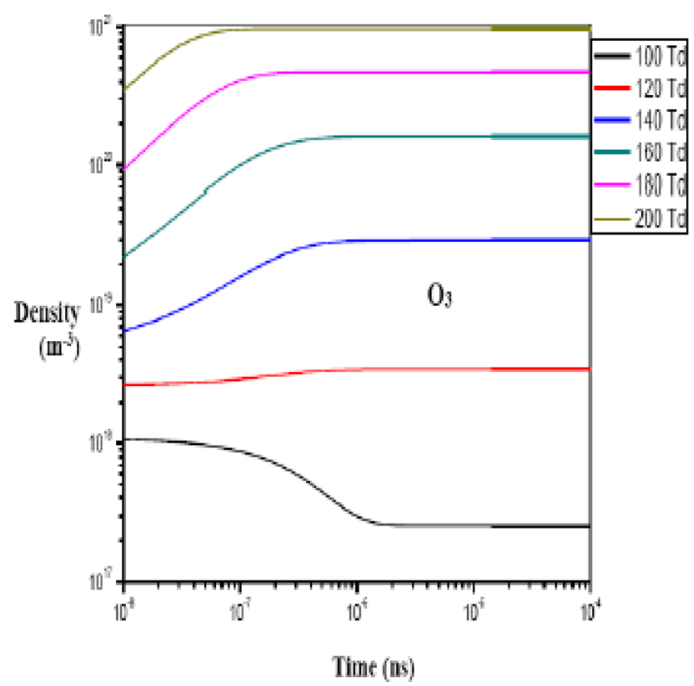

(b)

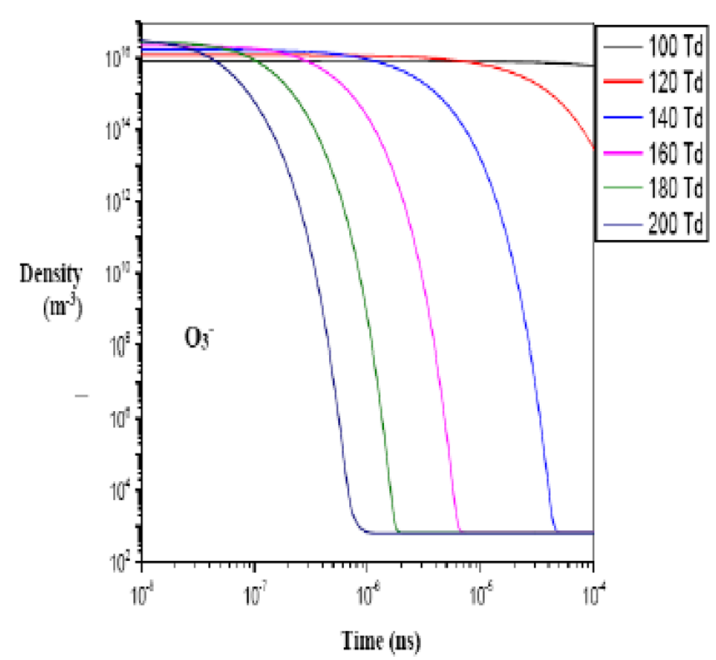

(d)

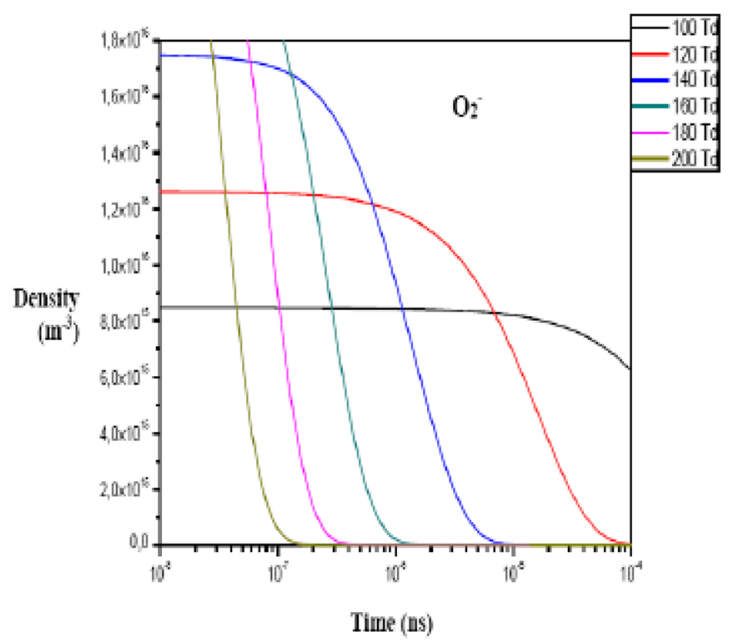

(f)

Fig. $1 \mathrm{O}, \mathrm{O}_{3}, \mathrm{O}_{2}\left(\mathrm{~A}_{1}\right), \mathrm{O}_{3}{ }^{-}, \mathrm{O}^{-}$and $\mathrm{O}_{2}{ }^{-}$species' density time evolution 


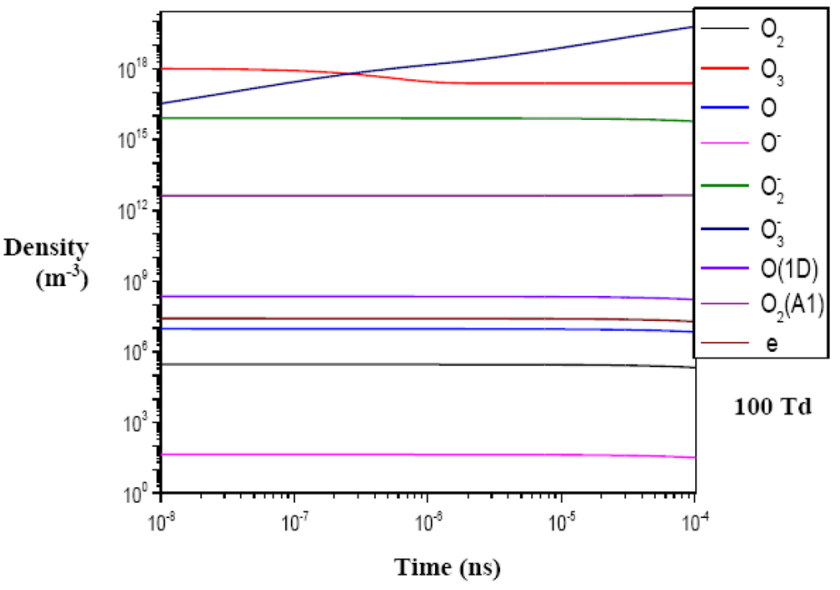

(a)

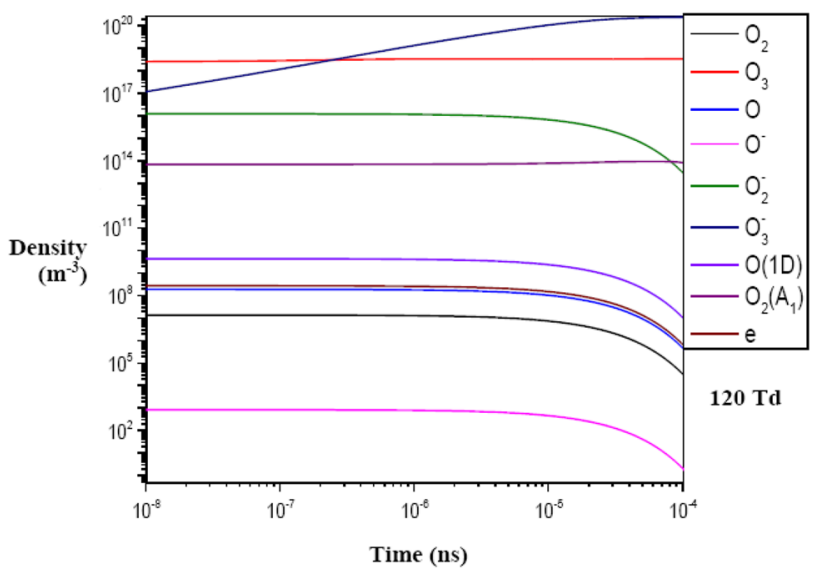

(b)

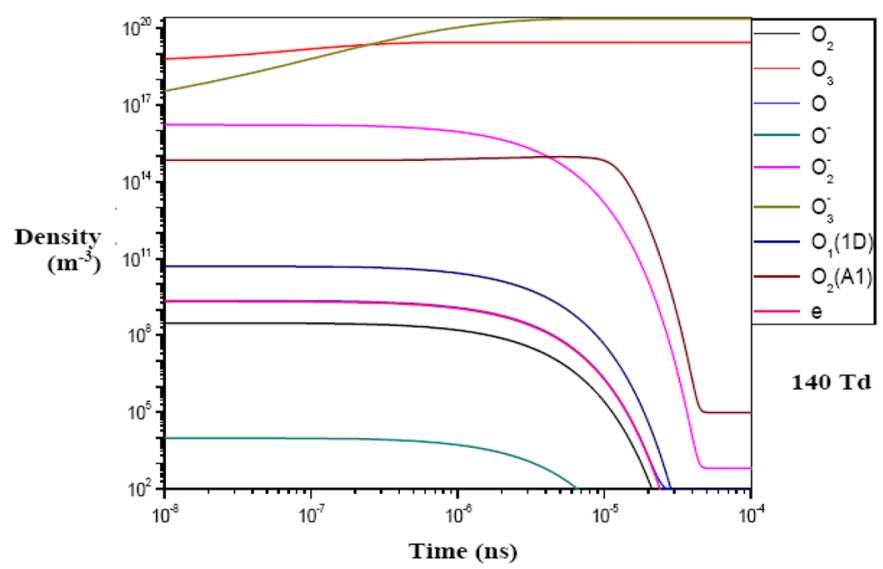

(c)

Fig. 2 Species' density time evolution at $100 \mathrm{Td}, 120 \mathrm{Td}$ and $140 \mathrm{Td}$

represents a critical voltage for the $\mathrm{O}_{3}{ }^{-}$production. It is also good to view better the creation of other species and consequently the consummation of each other (Fig. 2c). The density conservation histograms of $\mathrm{O}_{2}{ }^{-}, \mathrm{O}_{1} \mathrm{O}_{3}{ }^{-}$species upon the reduced electric field are given (Fig. $3 a-c)$. The $\mathrm{O}_{3}$ density conservation begins to appear with the first reduced field values and increases exponentially for higher values (Fig. 3d). At 160, 180, 200 Td, the electronic impact is very important where all the species are created and consequently are consumed continually unless the ozone $\mathrm{O}_{3}$ whose density increases exponentially upon $\left(\frac{E}{N}\right)$ higher (Fig. 4a-c). 


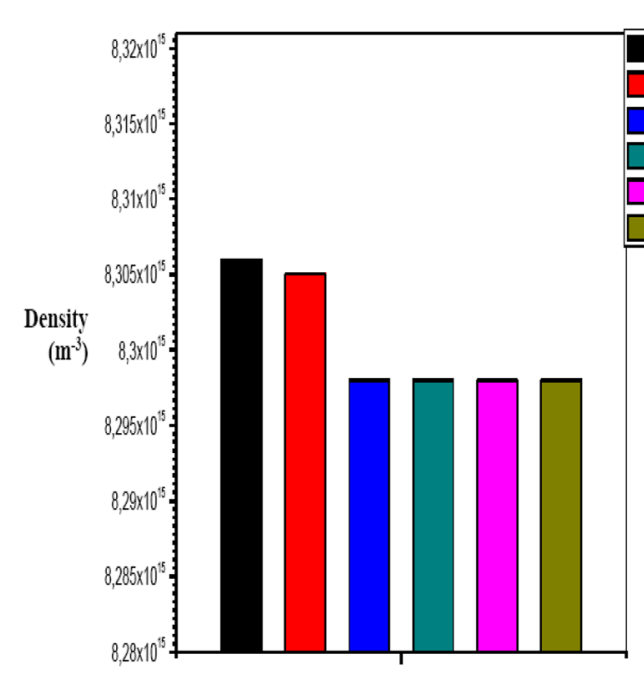

(a)

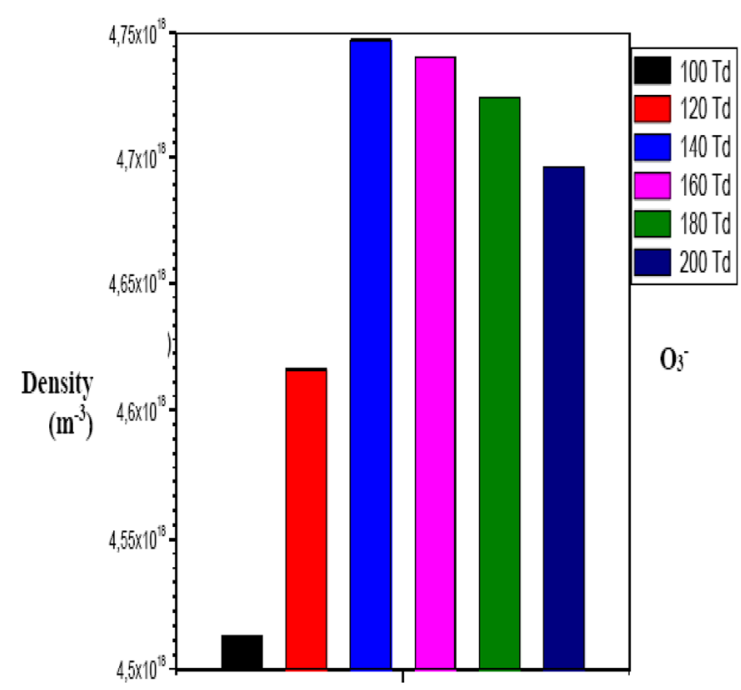

(c)

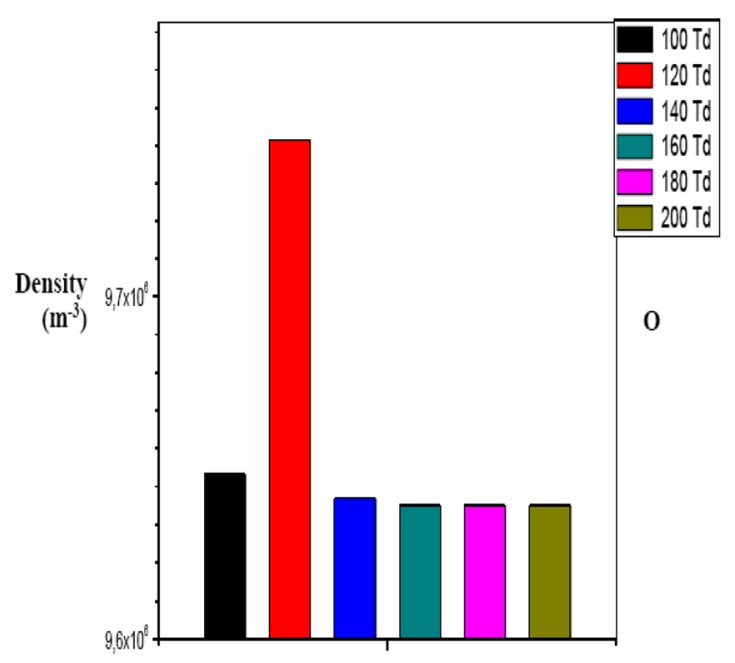

(b)

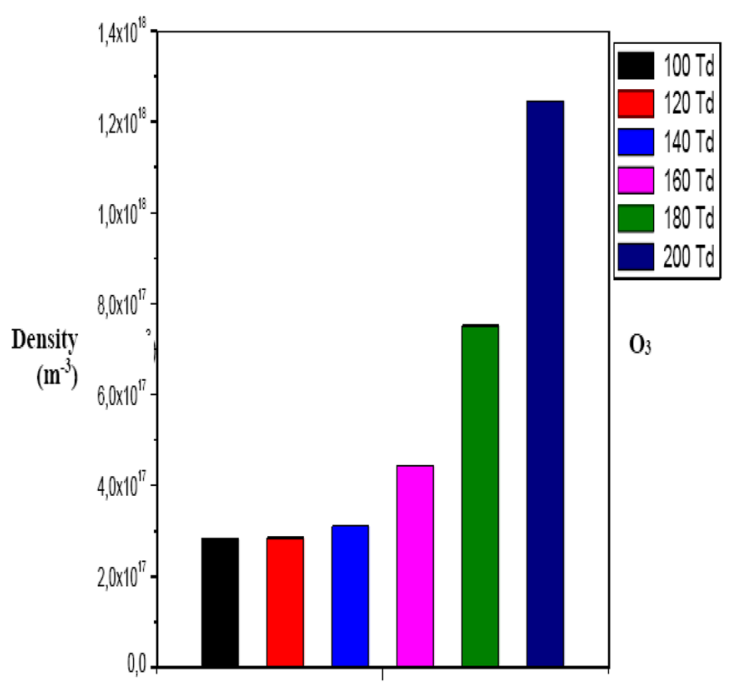

(d)

Fig. 3 Reduced field versus $\mathrm{O}_{2}{ }^{-}, \mathrm{O}_{1} \mathrm{O}_{3}{ }^{-}$and $\mathrm{O}_{3}$ species conservation histograms 


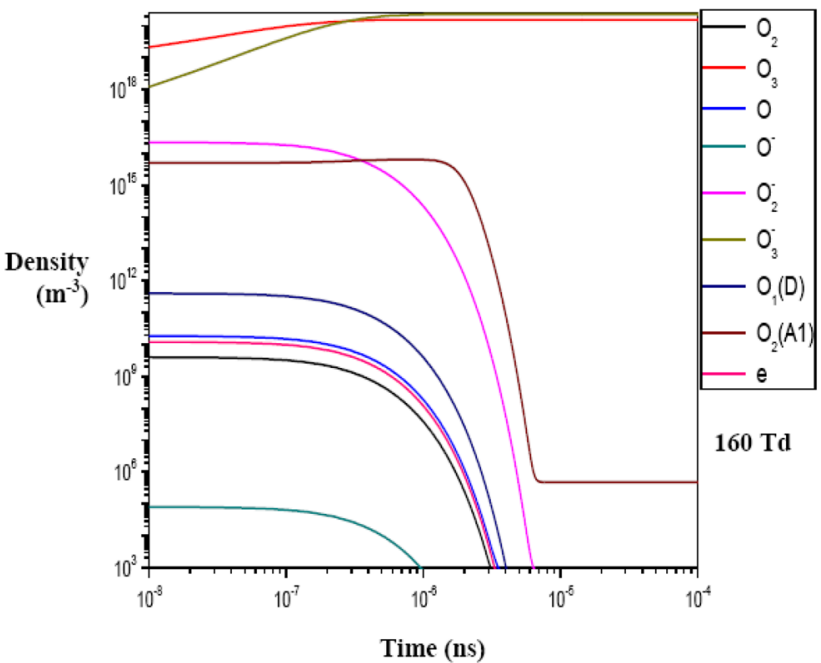

(a)

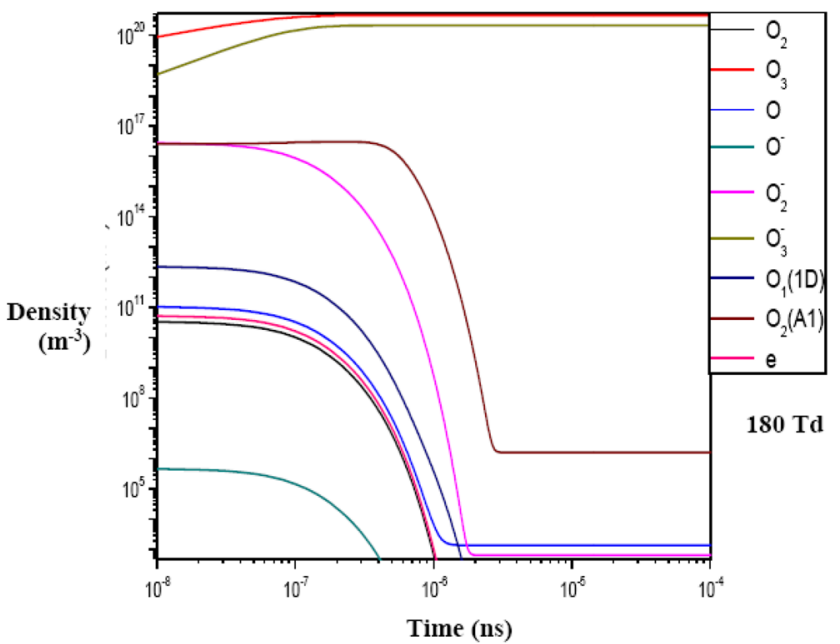

(b)

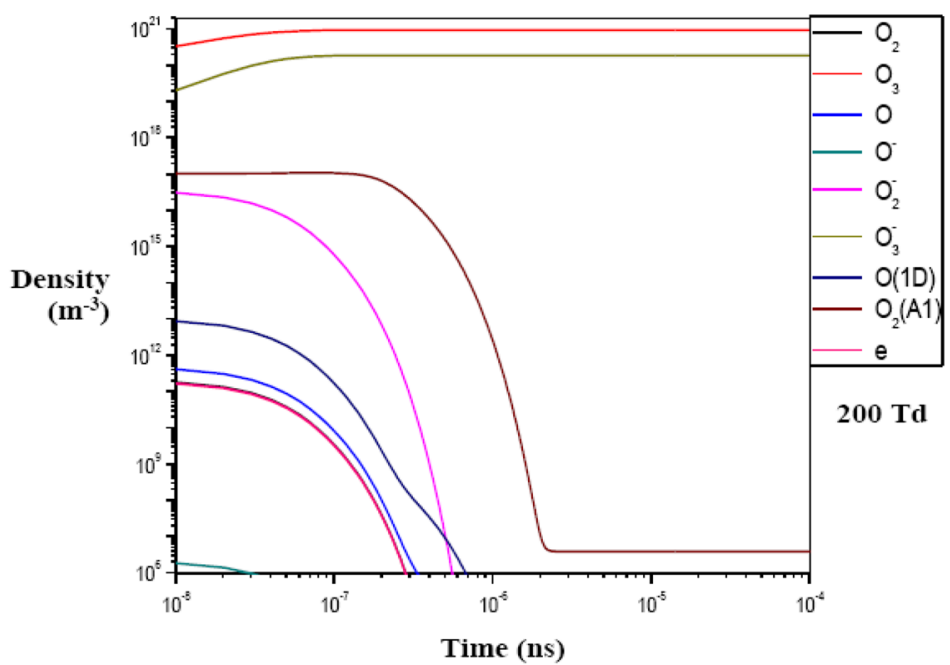

(c)

Fig. 4 Species' density time evolution at $160 \mathrm{Td}, 180 \mathrm{Td}$ and $200 \mathrm{Td}$

\section{Conclusion}

The effect of the reduced field values on the creation of the species studied by the method exposed in this paper is clearly noted and explained. The simulation was performed using a computer program, the results obtained show an evolution closely related to the reduced electric field $\left(\frac{E}{N}\right)$, and the production of ozone is accompanied by the appearance and disappearance of other species. Then, the exact voltage for the evolution of each of the neutral, ionic and excited states is evaluated. Thus, this study permits one to follow their chemical kinetics. Otherwise, it is showed clearly, for the $\mathrm{O}_{2}$ pure gas, the importance of the primary radical $\mathrm{O}$ and the secondary $\mathrm{O}^{-}$. These last are mainly responsible for ozone $\mathrm{O}_{3}$ creation. The $\mathrm{O}$ is created abundantly by electronic impact with $\mathrm{O}_{2}$ molecules. This species is generated quickly but is consumed rapidly too in gain of ozone molecule $\mathrm{O}_{3}$. This is quite possible only to a limit voltage and a reduced field $\left(\frac{E}{N}\right)=120 \mathrm{Td}$. For ozone molecule $\mathrm{O}_{3}$, we notice an intensive creation followed by its quiet concentration stability. The $\mathrm{O}_{3}$ density conservation begins to appear with the first reduced field values and increase exponentially for higher values. At 160, 180 and $200 \mathrm{Td}$, the electronic impact is very important where all the species are created and consequently are consumed continually unless the ozone $\mathrm{O}_{3}$ whose density increases exponentially for higher $\left(\frac{E}{N}\right)$ increases. 


\section{Compliance with ethical standards}

Conflict of interest On behalf of all authors, the corresponding author states that there is no conflict of interest.

\section{References}

1. Rogers BR, Cale TS (2002) Plasma processes in microelectronic device manufacturing. Vacuum 65:267-279

2. Chu PK (2009) Applications of plasma-based technology to microelectronics and biomedical engineering. Surf Coat Technol 203:2793-2798

3. Măgureanu M, Sîrbu R, Dobrin D, Gîdea M (2018) Stimulation of the germination and early growth of tomato seeds by nonthermal plasma. Plasma Chem Plasma Process 38:989-1001

4. Taylor PR, Pirzada SA (1993) Plasma technology in extractive and process metallurgy. Min Process Extr Metall Rev 12:257-269

5. Shimizu K, Fukugana H, Blajan M (2014) Biomedical applications of atmospheric microplasma. Curr Appl Phys 14:S154-S161

6. Mizeraczyk J, Jasiński M, Zakrzewski Z (2005) Hazardous gas treatment using atmospheric pressure microwave discharges. Plasma Phys Controll Fus 47:B589

7. Baranov OO, Xu S, Xu L, Huang S, Lim JWM, Cvelbar U, Levchenko I, Bazaka K (2018) Miniaturized plasma sources: can technological solutions help electric micropropulsion. IEEE Trans Plasma Sci 46:230

8. Kachi M, Dascalescu L (2014) Corona discharges in asymmetric electrode configurations. J Electrost 72:6-12

9. Anane Z, Bayadi A, Huang K (2018) Distortion phenomena on transmission lines using corona modeling ATP/EMTP. IEEE Trans Dielectr Electr Insul 25:383-389

10. Bouguila N, Coelho R, Navarre D (1993) Electrostatic painting of insulating surfaces. IEEE Trans Ind Appl 29:798-801

11. Hadji K, Pontiga F, Belasri A, Hadj-Ziane S, Fernandez R (2014) Experimental study of ozone generation by negative corona discharge in mixtures of $\mathrm{N}_{2}$ and $\mathrm{O}_{2}$. J Ozone Sci Eng 36:65-72

12. Hamade TA (2018) Novel electrically stimulated catalytic converter prototype of replacement of conventional auto exhaust emission converters. J Shanghai Jiaotong Univ 2:85-96

13. Ajo P, Kornev I, Preis S (2015) Pulsed corona discharge in water treatment: the effect of hydrodynamic conditions on oxidation energy efficiency. Ind Eng Chem Res 54:7452-7458

14. Agbaba J, Molnar J, Tubić A, Watson M, Maletić S, Dalmacija B (2015) Effects of water matrix and ozonation on natural organic matter fractionation and corresponding disinfection by-products formation. Water Sci Technol Water Supply 15:75-83

15. Wang $P$, Chen J (2009) Numerical modeling of ozone production in a wire-cylinder corona discharge and comparison with a wireplate corona discharge. J Phys D Appl Phys 42:035202
16. Yehia A, Mizuno A (2013) Ozone generation by negative direct current corona discharges in dry air fed coaxial wire-cylinder reactors. J Appl Phys 113:183301

17. Hadj-Ziane S, Held B, Pignolet P, Peyrous R, Benas JM, Coste $C(1990)$ Ozone production in an oxygen-fed wire to cylinder ozonizer. J Phys D Appl Phys 23:1390-1395

18. Hadj-Ziane S, Held B, Pignolet P, Peyrous R, Coste C (1992) Ozone generation in an oxygen-fed wire-to-cylinder ozonizer at atmospheric pressure. J Phys D Appl Phys 25:677-685

19. Loiseau JF, Lacassie F, Monge C, Peyrous R, Held B (1994) Numerical simulation of ozone axial and radial distribution in a cylindrical oxygen-fed ozonizer. J Phys D Appl Phys 27:63-73

20. Chen J, Davidson JH (2002) Ozone production in the positive dc corona discharge: model and comparison to experiments. Plasma Chem Plasma Process 22:495-522

21. Chen J, Davidson JH (2003) Ozone production in the negative dc corona: the dependence of discharge polarity. Plasma Chem Plasma Process. 23:501-18

22. Wang P, Chen J (2009) Numerical modelling of ozone production in a wire-cylinder corona discharge and comparison with a wire-plate corona. J Phys D Appl Phys 42:035202

23. Soria C, Pontiga F, Castellanos A (2004) Plasma chemical and electrical modelling of a negative dc corona in pure oxygen. Plasma Source Sci Technol 13:95-107

24. Yanallah K, Pontiga F, Fernández-Rueda A, Castellanos A, Belasri A (2008) Ozone generation by negative corona discharge: the effect of Joule heating. J Phys D Appl Phys 41:195206

25. Yanallah K, Pontiga F, Fernández-Rueda A, Castellanos A (2009) Experimental investigation and numerical modelling of positive corona discharge: ozone generation. J Phys D Appl Phys 42:065202

26. Guo Y (2004) The Boltzmann equation in the whole space. Indiana Univ Math J 53:1081-1094

27. Acharya S, Baliga BR, Karki K, Murthy JY, Prakash C, Vanka SP (2007) Pressure-based finite-volume methods in computational fluid dynamics. J Heat Transf 129:407-424

28. Boris J, Book DL (1973) Flux corrected transport I. SHASTA, a fluid transport algorithm that work. J Comput Phys 11:38-69

29. Boris J, Book DL (1975) Flux corrected transport II: generalization of the method. J Comput Phys 18:248

30. Boris J, Book DL (1975) Flux corrected transport III: minimal-error FCT algorithms. J Comput Phys 20:397-431

31. Eliasson B, Kogelschatz U (1986) Basic data for modelling of electrical discharges in gases: oxygen. Report KLR86-11C, Asea Brown Boveri Konzernforschung, CH54-05 Baden

Publisher's Note Springer Nature remains neutral with regard to jurisdictional claims in published maps and institutional affiliations. 